\title{
O NOVO ROMANCE HISTÓRICO LATINO- AMERICANO: A DESCONSTRUÇÃO DE UM PERFIL DEMONIZADO CONSTRUÍDO A PARTIR DAS CRÔNICAS DE 1559-1561
}

\author{
Gilmei Francisco Fleck ${ }^{*}$ \\ Alceni Elias Langner \\ Universidade Estadual do Oeste do Paraná
}

\begin{abstract}
Resumo: Ao analisar a obra Lope de Aguirre: Crónicas (1559-1561), de Mampel González e Escandell Tur (1981), propomos uma verificação do perfil deste conquistador europeu que dá nome à obra. Com enfoque principal em Aguirre, as seis crônicas relacionadas na obra apresentam o percurso e os acontecimentos da expedição de Pedro de Ursúa, em 1560, a qual tinha como missão encontrar as riquezas do El Dorado. Ao estabelecer um elo vital com a região do Peru, Aguirre, em uma carta à Coroa espanhola, desnaturaliza-se de seus domínios, fato que incide numa pré-declaração de independência do território americano. Devido aos rumos que a expedição tomou, Aguirre é traído e morto por seus companheiros, os quais escrevem textos repletos de condenações à fragmentada personagem. Dessa forma, essa investigação bibliográfica busca resgatar a imagem discursiva de Aguirre nas crônicas elencadas para, comparativamente com os dados destas crônicas, fazer remissões a romances históricos como Daimón, de Abel Posse (1978) e Lope de Aguirre: Príncipe de la Libertad, de Miguel Otero Silva (1979).
\end{abstract}

Palavras-chave: Novo Romance Histórico Latino-americano. Lope de Aguirre. Crônicas (1559-1561). Daimón (1978). Lope de Aguirre: Príncipe de la Libertad (1979).

\footnotetext{
(c) (1) Esta obra está licenciada sob uma Creative Commons - Atribuição 4.0

* Professor Associado da UNIOESTE/Cascavel na Graduação e Pós-graduação em Letras nas áreas de Literatura e Cultura Hispânicas. Pós-doutor em Literatura Comparada e Tradução pela UVigo/ Vigo-Espanha, com bolsa da CAPES, Doutor em Letras pela UNESP/Assis. Coordenador do PELCA: Programa de Ensino de Literatura e Cultura e coordenador do projeto de pesquisa "Ressignificações do passado na América: leitura, escrita e tradução de gêneros híbridos de história e ficção- vias para a descolonização". E-mail: chicofleck@yahoo.com.br.

** Graduado em Letras - Português/Espanhol pela Universidade Federal da Fronteira Sul (Campus Realeza-PR). Aluno do Programa de Pós-graduação em Letras, Nível de Mestrado da UNIOESTE (Campus Cascavel-PR); Atuante na linha de pesquisa Linguagem Literária e Interfaces Sociais: Estudos Comparados. Especialista em Literatura Brasileira e Infantil pela FSB. Integrante do grupo de pesquisa "Ressignificações do passado na América Latina: leitura, escrita e tradução de gêneros híbridos de história e ficção - vias para a descolonização", coordenado pelo Prof. Dr. Gilmei Francisco Fleck. Colaborador do projeto de extensão "Estudos das teorias contemporâneas de análise literária - segunda fase", vinculado ao PELCA - Programa de Ensino de Literatura e Cultura/PROEX-Unioeste-Cascavel. Aluno bolsista da CAPES. E-mail: alcenilang@hotmail.com.
} 


\section{Introdução}

Entre os séculos XV e XVI, com o início das grandes navegações e descobrimentos, a conjuntura sequencial das conquistas resultou em um "Novo Mundo" à disposição dos poderes monárquicos europeus. Séculos se passaram para que se dessem início às revoluções e declarações de independência dos territórios americanos incorporados às coroas europeias naquele momento. A escrita da história, realizada pela parcela conquistadora, empenhou-se em memorar e resguardar esses eventos por meio de cartas, crônicas e relações escritas pelos navegantes, expedicionários, viajantes e aventureiros que cruzaram o Atlântico e realizaram aqui as suas "proezas". No entanto, esse material é construído com base em um discurso tendencioso, cujo pragmatismo positivista se volta à ideia da hegemonia dos descobridores frente à colônia, estes representados, especificamente, pelas Coroas espanhola e portuguesa, responsáveis pela colonização de quase todo o território Latino-americano.

Ao averiguarmos algumas das crônicas e relações, publicadas até o século XX, as quais narram as jornadas das colonizações espanholas na América Latina, especificamente a Jornada de Omagua y Dorado (1986), deparamo-nos com a personagem histórica Lope de Aguirre. De acordo com os registros históricos (Mampel González; Escandell Tur, 1981), essa personagem chega ao "Novo Mundo" para servir à Coroa espanhola no processo de apropriação da colônia. Para tanto, Aguirre acaba se alistando como um dos integrantes da expedição comandada por Pedro de Ursúa, a qual ocorreu entre 1559-1560. Tal expedição foi organizada na ilusória intenção de descobrir as riquezas prometidas pelo mítico reino de Omagua e El Dorado.

De acordo com o relato das crônicas (MAMPEL GONZÁLEZ; ESCANDELL TUR, 1981), Aguirre acaba se rebelando contra a Coroa, na época representada pelo rei Felipe II, projetando-se, nos registros historiográficos, como um dos principais incitadores à independência do Vice-Reino do Peru, o qual compreendia toda a extensão entre Equador, Peru e Chile. Aguirre rompe com os ideais do colonizador e assume uma postura libertária em defesa da região, juntamente com seus seguidores, conhecidos como marañones. Esse fato é mencionado já no prólogo da obra Lope de Aguirre: crônicas (1559-1561), de Mampel González e Escandell Tur (1981, p. v), no qual as autoras reiteram que "[...] la gente que traía era de Piru [...]"1, o que coloca Aguirre no patamar de defensor da região, em igualdade com os nativos, e não com o status singular de conquistador. Contudo, essa atitude de rebeldia rendeu-lhe a imagem de anti-herói no discurso historiográfico.

\footnotetext{
${ }^{1}$ Nossa tradução livre: $[\ldots .$.$] o povo que traía era do Peru [...].$
} 
Com um perfil construído sob contradições, dúvidas e polêmicas, as quais se perpetuaram ao longo dos séculos, numa construção discursiva que revela o limiar tênue entre a loucura e a barbárie, a existência de Aguirre é transformada em mito, cuja base está nos relatos dos expedicionários, registrados nas crônicas que narram a jornada dos exploradores espanhóis, principalmente a de Francisco Vasquez e Pedrarias de Almesto. A publicação dessa crônica se deu com o título de Jornada de Omagua y Dorado: Crónica de Lope de Aguirre ([1562] 1986). Tal crônica é considerada por críticos como Jos (1927), a mais fiel entre todas.

Dessa forma temos uma dubiedade nos fatos ocorridos na expedição que, por um lado se pode considerar como a luta pela independência do Peru e, por outro, a pura tirania de um ser demonizado. Essas crônicas perpetraram os feitos da personagem, os quais se mesclam com um contexto mágico, enaltecido em hipérboles aplicadas à fauna e flora, e a metais preciosos até então de existência duvidosa e localização imprecisa. Contudo, a distinção com que essa personagem é tratada em diferentes representações, a literária e a histórica, ficará visível no decorrer de nossa análise.

\section{Aguirre: a configuração do tirano na historiografia}

Ao elencar as seis crônicas publicadas na obra de Mampel González e Escandell Tur (1981), temos a seguinte organização: crônica de Gonzalo de Zúñiga (1561); crônica de Toribio de Ortiguera (1586); crônica de Pedro de Monguia (1561); crônica de Custodio Hernández (1562); crônica de Francisco Vázquez/Pedrarias de Almesto (1562); e a última de autoria anônima (1561). Apesar das datas de escritura das crônicas divergirem entre si, possivelmente a maioria delas começa a ser escrita após 27 de outubro de 1561, data em que Aguirre tem sua cabeça decepada pelas mãos de Custódio Hernández, o que dá por encerrada qualquer tipo de rebelião naquele momento.

Em virtude da intenção da escritura dessas crônicas, que era se eximir da culpa pela traição à coroa espanhola e, ao mesmo tempo, cortar qualquer elo ideológico que ligasse os autores a Lope de Aguirre, todos os textos apresentam uma forte marcação ideológica judaico-cristã. Essa é uma das características que nos permite identificar esse apelo ao discurso ético e moral, influenciado pelo cristianismo, na tentativa satisfatória de causar o contraste entre um tirano movido por forças demoníacas, e reles soldados de bem, que, mesmo submissos a essa força, mantiveram sua ideologia cristã intacta.

É fácil chegar a tal dedução quando relacionamos a questão ideológica com a intenção de produção dessas crônicas e com as condições de sua produção, que são as 
principais responsáveis pela interpretação histórica que acarreta na demonização de Aguirre. Em Barquisimeto, a Coroa espanhola vence Lope devido à traição de muitos de seus marañones, os quais, com tal ato, esperam pelo perdão de Felipe II. No entanto, para se eximir da culpa, era necessário que alguém assumisse as vidas perdidas durante a expedição, inclusive de pessoas importantes como Ursúa e Guzmán. Nesse sentido, as crônicas passam a ser escritas dentro de uma formatação que prioriza o relato dos assassinatos e a tirania no exercício do poder. Tais aspectos são impulsionados, direta ou indiretamente, somente para uma pessoa, o que nos dá como resultado a identidade histórica de Lope de Aguirre, a quem se sobrecarrega com toda a culpa.

Nesse ponto temos o conflito entre historiadores e literatos, pois, enquanto para alguns, incluindo-se a historiografia, Aguirre é tido como um ser tirânico e cruel, para outros, e nesse caso a literatura latino-americana, a personagem é uma das principais referências de libertação e independência da América, seja por seus ideais revolucionários ou, ainda, por provas autênticas de libertação, como a carta que escreveu ao rei da Espanha, considerada por Bolívar como o primeiro documento de manifesto libertário na América. Contudo, para que compreendamos as formas como essa imagem é construída, é necessário atentar para aspectos particulares, narrativos e estruturais, que cada crônica apresenta.

A primeira crônica, de Gonzalo de Zúñiga (1561), apresenta-se dividida claramente em dois momentos: um primeiro, dedicado à narrativa da jornada em caráter descritivo, e um segundo, voltado a um panorama quantitativo das mortes causadas por Aguirre, o que reforça a formatação de uma identidade demonizada. Essa configuração, contudo, não se concluiu, visto que o período histórico que a crônica abrange se inicia com a nomeação de Pedro de Ursúa a governador, até a chegada da expedição à Ilha de Margarita, em junho de 1561.

Quanto ao tratamento dado à personagem central, não se economizam descrições para o retratar como um ser demonizado. Nessa crônica, os termos que são utilizados com maior frequência para referir-se a Aguirre são "o tirano" e "o cruel tirano", conforme podemos observar: "Estando de partida, se ordenó un motin contra el cruel tirano [...]. El cual el dicho tirano lo sintió y supo del demonio, segundo paresció, por que dijo que á media noche lo había sentido en su corazón."2 (MAMPEL GONZÁLEZ; ESCANDELL TUR, 1981, p. 18). Caricato que era, a crônica amplia ainda mais as características físicas de Aguirre, relacionadas à baixa estatura e a deficiência em uma das pernas, consequência de um combate:

\footnotetext{
${ }^{2}$ Nossa tradução livre: Estando de partida, ordenou-se um motim contra o cruel tirano [...]. O qual o sentiu o dito tirano e soube pelo demônio, como pareceu, por que disse que à meia noite havia sentido em seu coração.
} 
Es el cruel tirano un hombre pequeño de cuerpo, muy mal agestado, cojea de un pié questá manco dél, y de las manos de muchos arcabuzazos que le han dado en batallas en Pirú [...]; teníanle por chocarrero y hechicero y grande amotinador [...]. ${ }^{3}$ (MAMPEL GONZÁLEZ; ESCANDELL TUR, 1981, p. 26).

Essas imperfeições, somadas ao perfil que a crônica constrói da personagem, produzem uma imagem discursiva inteiramente deslocada do seu papel de libertador da América, afastando-se, por exemplo, da imagem bem elaborada de Pedro de Ursúa, que possuía um bom porte físico e tem sua beleza enaltecida por seduzir a belíssima Inés de Atienza, a qual era desejada por muitos dos expedicionários. Nesse sentido, também encontramos esses aspectos na crônica de Toribio de Ortiguera (1586), como veremos adiante.

Esta segunda crônica elencada traz, logo no início, o seu destinatário: Don Felipe III, príncipe da Espanha. De acordo com a breve introdução realizada pelas autoras, essa crônica teria sido escrita como um presente ao monarca, que era filho do rei Felipe II, por isso só foi concluída tardiamente. Isso permitiu ao autor um tratamento rebuscado, tanto em aspectos formais quanto linguísticos. Isso fica perceptível na forma como a crônica foi estruturada, a começar pela sua extensão, com 62 capítulos, e cada um deles com uma epígrafe explicativa de seu conteúdo.

De forma análoga, este estilo pode ter servido como base para o escritor argentino Abel Posse na escrita de seu romance Daimón (1978), não só pelas semelhanças formais, mas pela simbologia que se manifesta no ato da desconstrução de um texto dado à Coroa como presente ainda no período colonial, e isso se dá no trabalho do autor com o novo romance histórico latino-americano, gênero este que, conforme Aínsa (1991), tem a liberdade para reler e reescrever a historiografia, pois "[...] la nueva narrativa, a través de un deliberado revisionismo relee y reescribe esa historia, oficial, desde el diario de Colón, crónicas y relaciones, hasta textos contemporáneos como los de la revolución mexicana". 4 (AÍNSA, 1991, p. 11).

No que diz respeito à narrativa, a crônica não se limita a narrar apenas os fatos comuns às outras, mas vai além, pois, ao relatar o desfecho da expedição, faz uma clara alusão a um castigo enviado pelos céus, o qual se manifesta em forma de vulcão próximo à cidade de Quito, em 1582. Essa conclusão se torna interessante pela intensidade com que a

\footnotetext{
${ }^{3}$ Nossa tradução livre: É o cruel tirano um homem de baixa estatura, muito mal apresentável por causa de um pé que está manco dele, e das mãos por muitos arcabuzadas que deram-lhe em batalhas no Peru [...]; tinham-no por vulgar, feiticeiro e amotinador [...].

${ }^{4}[\ldots]$ a nova narrativa, através de um deliberado revisionismo, relê e reescreve essa história, oficial, desde o diário de Colombo, crônicas e relações, até textos contemporâneos como os da revolução mexicana.
} 
sequência de culpa, castigo e perdão são tratados. O autor da crônica utiliza esse recurso a fim de mostrar que, pelo fato da expedição ter sido cruel com a vida de muitos, houve, ainda, um sofrimento posterior para remir a culpa inicial.

Quanto a polidez do escritor da crônica, ela não se restringe ao quesito estrutural e à escrita impecável, mas evidencia-se também nos adjetivos utilizados para referir-se a Lope de Aguirre, já que o termo "tirano" surge apenas nas partes finais do texto, antes disso a personagem é trazida à narrativa pelo nome. No entanto, isso não diminui a demonização construída sobre Lope: “Mas como Lope de Aguirre reconoció su perdición, [...] luego se tuvo por perdido y con ánimo y furia infernal [...]"5 (MAMPEL GONZÁLEZ; ECANDELL TUR, 1981, p. 149), pois mesmo tratado pelo nome, os condicionantes o demonizam e o colocam como um ser de fúria infernal: "[...] Y como se viese perdido y que en ninguna manera se podía escapar, con un despecho del más atroz y cruel tirano que jamás hasta él se vió."6 (MAMPEL GONZÁLEZ; ESNCADELL TUR, 1981, p. 149).

Nesse estudo de revisitação às crônicas que se referem a Lope de Aguirre o que pode ser colocado em evidência são as formas como a referenciação ao sujeito é feita. Nessa ótica, a terceira crônica elencada, a de Pedro de Monguia (1561), distancia-se das demais por dar suma importância aos discursos proferidos por Fernando de Guzmán, segundo governador após a morte de Ursúa, e por Aguirre durante a jornada. Entretanto, em virtude da fuga e traição de Monguia, a crônica é breve e narra, apenas, o período histórico-narrativo em que o cronista esteve na expedição: da nomeação de Pedro de Ursúa a governador, até a chegada à Ilha de Margarita e posterior delato ao frei Francisco Montessinos, responsável por proporcionar a derrocada da missão idealizada por Lope.

Com relação ao tratamento dado à personagem, alguns dos adjetivos utilizados são "el tirano" e "el dicho", mas o que o cronista deixa bem explícito é o caráter persuasivo de Aguirre: “[...] le quitaron el cargo de Maese de campo é se lo dieron al Juan Alonso, é aún fueron en acuerdo de matar à Lope de Aguirre, el cual los venció con palabras melosas é con anteciparse á exemirse del cargo."7 (Mampel González; Escandell Tur, 1981, p. 179). Nesse mesmo sentido, a personagem é tratada como um assassino impiedoso que, além de coletar informações, também executa mortes à sua própria razão: “[...] insistió Lope de Aguirre á D.

\footnotetext{
${ }^{5}$ Mas como Lope de Aguirre reconheceu sua perdição, [...] logo se viu como perdido e com ânimo e fúria infernal [...].

${ }^{6}$ Nossa tradução livre: [...] E como se como se enxergasse perdido e sem nenhuma maneira de escapar, com um despeito de tirano mais cruel e atroz que jamais se viu como ele [...].

${ }^{7}$ Nossa tradução livre: [...] tiraram-lhe o cargo de Chefe de campo e deram a Juan Alonso, e ainda entraram em acordo de matar Lope de Aguirre, o qual venceu-lhes com palavras melosas e com anteciapar-se a exismir-se do cargo.
} 
Fernando que Juan Alonso lo quería matar [...] “¿qué remédio habrá para ello?” respondió Lope de Aguirre que le diese licencia, quél daria remédio. [...]."» (Mampel González; Escandell Tur, 1981, p. 179).

Na crônica de Custodio Hernández (1562), apesar de apresentar toda a jornada, identificamos uma clara divisão estrutural: primeiramente são narrados os feitos e passos de Ursúa e, em um segundo momento, adentramos no espaço de Aguirre, o qual, comumente, recebe os adjetivos depreciativos e demonizados das demais crônicas: "Ya lope daguirre andaua aqui tan feroz que nadie osaua hablarle [...]."9 (Mampel González; Escandell Tur, 1981, p. 197). No entanto, uma das especificidades dessa crônica é a atenção que é dedicada às personagens femininas da jornada: Inés de Atienza, a amante de Ursúa, e Elvira, a filha de quinze anos de Aguirre.

Essa característica da crônica se torna importante quando a aproximamos de romances históricos como Lope de Aguirre: príncipe de la libertad, de Otero Silva (1979), e Daimón, de Posse (1978), nos quais essas personagens exercem papel fundamental e decisivo no decorrer da jornada, por meio do experimentalismo dos autores. Atienza tem sua imagem associada à sedução dos soldados da expedição, fato que resultou, inclusive, na morte de Ursúa, já Elvira tinha um elo fraternal com Aguirre e, segundo Neira (2013, p. 59), foi a única pessoa por quem a protagonista teve amor verdadeiramente.

Como base para algumas das crônicas, o texto de Francisco Vázquez e Pedrarias de Almesto (1562) - embora envolto em discussões sobre a sua autoria, por possuir uma das melhores descrições espaço-temporais, uma linearidade histórico-narrativa convincente, além de ricos dados historiográficos dentro de uma narrativa longa - acabou por ser a crônica mais publicada. Isso se dá, inclusive, em livro próprio sob o título de Jornada de Omagua y Dorado: crónica de Lope de Aguirre (1986).

No texto, o epíteto de cruel tirano à personagem é criado de forma gradual. No entanto, o autor reserva as últimas páginas para descrever Aguirre, o qual é tido como inimigo dos benfeitores, cruel, perverso e pagão, isso por ter vendido a alma ao diabo, uma das qualidades mais reaproveitadas nos novos romances históricos:

Era este tirano Lope de Aguirre hombre casi de cincuenta años, muy pequeño de cuerpo, y poca persona; mal agestado, la cara pequeña y chupada; los ojos que si miraba de hito le estaban bullendo en el casco especial cuando estaba enojado. [...] fue tan cruel y perverso, que no se halla ni puede notar en él cosa buena ni de

\footnotetext{
${ }^{8}$ Nossa tradução livre: [...] insistiu Lope de Aguirre a D. Fernando que Juan Alonso o queria matar [...] 'Que remédio haverá para isso?' Respondeu Lope de Aguirre que desse-lhe licença, que ele daria remédio. [...]”

${ }^{9}$ Nossa tradução livre: Já Lope de Aguirre andava aqui tão feroz que ninguém ousava falar com ele. [...].
} 
virtud. [...] Era naturalmente enemigo de los buenos y virtuosos, y ansí, le parecian mal todas las obras santas [...] Tuvo por vicio ordinario encomendar al demonio su alma y cuerpo y persona, nombrando su cabeza, piernas y brazos, y lo mismo sus cosas. ${ }^{10}$ (MAMPEL GONZÁLEZ; ESCANDELL TUR, 1981, p. 270).

Essa condenação da personagem nas crônicas, no que tange ao seu pacto com o diabo, encontra uma clara divergência nos novos romances históricos já mencionados de Posse (1978) e Otero Silva (1979), nos quais a figura do diabo torna-se personagem íntimo de Aguirre, responsável por controlar os impulsos emocionais e por alertá-lo quanto às ameaças e traições corriqueiras na expedição. A nomeação do diabo, no primeiro romance "Bajíssimo" e no segundo "Mandrágora", é uma das características que revela a importância dada a tal personagem.

Em suma, dentre as narrativas das crônicas, o que mais causa espanto no leitor é o teor quantitativo ligado às mortes, sempre atreladas a Aguirre. Na última crônica da obra, a Anônima (1561), essa questão é posta em evidência, pois, em poucas páginas, o autor elabora uma pequena lista contendo todas as mortes, atreladas à forma como foram executadas. Isso, de certa forma, sana o desejo do autor em construir o demônio tirano, não só pelo modo de execução, mas pelos números tão aclarados.

\section{O mito tirânico desconstruído: Aguirre no novo romance histórico latino-americano}

É importante ressaltar o valor do boom na literatura latino-americana, o qual teve seu ápice na década de 70, e com ele o surgimento de umas das modalidades do gênero romance histórico: o novo romance histórico latino-americano, que passa a ser objeto de estudo de críticos literários como Amado Alonso (1984), Aínsa (1991) e Menton (1993). Assim sendo, Menton, em sua obra La nueva novela histórica de la América Latina, 1979-1992, elenca as principais características dos novos romances históricos, antes já estabelecidos por Aínsa (1991) em uma longa lista de 10 peculiaridades. Essas foram sintetizadas na versão de Menton (1993, p. 42-46) e podem ser resumidas como segue:

1 - La subordinación de la reproducción mimética de cierto periodo histórico a la presentación de algunas ideas filosóficas. 2- La distorsión consciente de la historia mediante omisiones, exageraciones y anacronismos. 3- La ficcionalización de personajes históricos, a diferencia de la fórmula de Walter Scott de incluir protagonistas ficticios. 4. La metaficción o los comentarios del narrador sobre el proceso de creación. 5. La intertextualidad. 6. Los conceptos bajtinianos de lo

\footnotetext{
${ }^{10}$ Nossa tradução livre: Era esse tirano Lope de Aguirre homem quase de cinquenta anos, muito pequeno de corpo, e pouca personalidade; de aparência ruim, a cara pequena e chupada; os olhos que fitavam estavam fervilhantes no capacete especial quando estava zangado. [...] foi tão cruel e perverso, que não se acha nem pode notar nele coisa boa nem virtude. [...] Era naturalmente inimigo dos bons e virtuosos, e assim, pareciam-lhe más todas as obras santas [...]. Teve por vício ordinário encomendar ao demônio sua alma e corpo e personalidade, fechando sua cabeça, pernas e braços, assim como suas costas.
} 
dialógico, lo carnavalesco, la parodia y la heteroglossia. ${ }^{11}$

É com base nas características e definições desses críticos que podemos aproximar os romances Daimón, de Abel Posse (1978), e Lope de Aguirre: príncipe de la libertad, de Miguel Otero Silva (1979) dos objetivos e experimentações formais e linguísticas que os autores propuseram com suas escritas nesse gênero. Para essa afirmação encontramos respaldo em autores como Esteves (1995) bem como em Tacconi (2013).

Nesse sentido, ambos os romances têm sua projeção em uma linha narrativa que desconstrói o mito tirânico que os escritores das crônicas tanto se empenharam em materializar. A obra de Otero Silva (1979), embora possua uma linearidade histórico-temporal demarcada, resgata o passado de Aguirre de forma a recriar sua trajetória, e isso não o conduz à tirania, mas ao patamar de libertador do Peru. Já no romance de Posse (1978), em uma narrativa atemporal e paródica, trabalha-se com o experimentalismo formal ao inserir as personagens em uma espécie de simulacro, no qual o contexto e o tempo histórico perdem a importância. Essas características, tão imbricadas nos romances, contribuem para uma cisão evidente com as crônicas, pois deixam de lado o valor agregado às informações historiográficas que, em textos como o de Vázquez e Almesto (1562), é elementar.

Em específico, o texto de Otero Silva (1979), inicia-se com a apresentação da personagem ainda jovem e em processo de maturação, isso em um contexto familiar. Essa introdução marca o momento da alteração da identidade de Aguirre, o qual sai da condição de provincial basco, para se tornar um libertador no "Novo Mundo", aventurando-se pelas ruas de Sevilha. Nesse contexto, o autor elabora uma série de enfrentamentos para a personagem, dos quais a falta de instrução e a miséria soam como os principais motivadores para o desencadeamento de ações decisivas em sua trajetória. Na obra, o caráter humilde da personagem é construído por suas próprias ações ao longo do texto, representado ora por suas relações, ora por suas atitudes:

Durante no poco tiempo, pongamos un ano, Lope de Aguirre malbarato las suelas de sus zapatos en callejas y avenidas, se cruzaba de día y de noche con frailes enfermos que pedían limosna y rezaban credos innecesarios. [...] Lope de Aguirre dormía de espaldas sobre los tablones, si no dormía contaba resignadamente las estrellas, escuchaba la voz desgastada del otro vagabundo, un viejo asturiano que

\footnotetext{
${ }^{11}$ Nossa tradução livre: 1 - A subordinação da reprodução mimética de certo período histórico até a apresentação de algumas ideias filosóficas. 2- A distorção consciente da história mediante omissões, exagerações e anacronismos. 3- A ficcionalização de personagens históricos, diferentemente da fórmula de Walter Scott de incluir protagonistas fictícios. 4. A metaficção aos comentários do narrador sobre o processo de criação. 5. A intertextualidade. 6. Os conceitos Bakhtinianos do diálogo, a carnavalização, a paródia e a heteroglossia.
} 
recitaba romances de desengaño y muerte. ${ }^{12}$ (OTERO SILVA, 1979, p. 109).

Quase como uma consequência, um instinto rebelde se desperta em Aguirre, condição esta que é desencadeada, principalmente, pelo fracasso pessoal, pois, por mais empenho e força de vontade que demonstrasse, seu ingresso para a América só aconteceria se a estatal "Casa de Contratação" enxergasse no pequeno basco um expedicionário em potencial, tal qual era a sua ambição. Conforme aponta a crítica Crespo Solana (1996), essa empresa estatal espanhola era a responsável pelo controle portuário, pela arrecadação de impostos e, principalmente, pelas atividades ligadas ao "Novo Mundo", ou seja, era o principal percalço no caminho da personagem.

Tú, Lope de Aguirre, morabas en un corral de vecinos, dormías en el más mugriento arrabal de Triana, para volver a tu casa era inevitable saltar por sobre basureros y gatos muertos, abrirse paso por entre nieblas de pestilencia y llantos de mendigos, apartar brutalmente a los enfermos reales y ficticios que te cerraban el camino, la Casa de la Contratación archivaba cuidadosamente tus solicitudes y tus imprecaciones, al final se te consumió la paciencia y te fuiste a vivir con los gitanos. ${ }^{13}$ (OTERO SILVA, 1979, p. 110).

Como uma espécie de preparação, na obra de Otero Silva (1979), esse período de convívio com os ciganos será fundamental para a sua partida ao além-mar, pois é com eles que aprende as técnicas de domar cavalos, profissão esta que lhe será de grande valia em outros contextos. A desconstrução do mito demonizado, todavia, será concluída ao fim do romance, quando o narrador retoma a valentia de Aguirre "soldado peruleiro", com a intenção de ressaltar que a vida vale menos do que a liberdade conquistada:

[...] Lope de Aguirre, rebelde forjado en el yunque perulero, guerrero herido en el valle de Chuquinga, general y cabeza de los invencibles marañones, tú has de probar en este trance último que eres un legítimo nacido de la raza vascongada, un digno emulo del feroz Miguel Arcángel, el brazo ejecutor de la ira de Dios. ${ }^{14}$ (OTERO SILVA, 1979, p. 316).

\footnotetext{
${ }^{12}$ Nossa tradução livre: Durante não pouco tempo, aproximadamente um ano, Lope de Aguirre gastou suas solas de sapatos em ruelas e avenidas, cruzada de dia e de noite com freis enfermos que pediam esmola e rezavam credos desnecessários [...] Lope de Aguirre dormia de costas sobre os quadros, se não dormia, contava resignadamente as estrelas, escutava a voz desgastada do outro vagabundo, um velho asturiano que recitava romances de desengano e morte.

${ }^{13}$ Nossa tradução livre: Você, Lope de Aguirre, morava em um curral de vizinhos, dormia no mais encardido subúrbio de Triana, para voltar à sua casa era inevitável saltar sobre lixeiros e gatos mortos, abrir caminho por entre nevoas de pestes e choros de mendigos, apartar brutalmente os doentes reais e falos que fechavam o caminho, a Casa de Contratação arquivava suas solicitações, por fim consumiu sua paciência e você se foi viver com os ciganos.

${ }^{14}$ Nossa tradução livre: [...] Lope de Aguirre, rebelde forjado no yunque peruleiro, guerreiro ferido no vale de Chuquinga, general e cabeça dos invencíveis marañones, você há de provar nesse último transe que é um legítimo nascido da raça vascongada, um digno seguidor do feroz Arcanjo Miguel, o braço executor da ira de Deus.
} 
Da mesma forma, o segundo romance sumariamente mencionado, Daimón, de Posse (1978), atua para ilidir essa identidade tirânica forjada pelas crônicas. No entanto, logo no início da obra, em um tipo de prólogo, o autor insere um texto biográfico da personagem, o qual apresenta todo o conjunto de traços idiossincráticos, responsáveis por sua demonização:

Lope de Aguirre (1513?-1561). Denominóse el Tirano, el Traidor, el Peregrino. Antiimperialista, declaró guerra desde la selva amazónica, rodeado de monos, a Felipe II, fundando de hecho "el primer territorio libre de América". Demonista. Erotómano tímido pero tenaz. Rebelde. Su crueldad es proverbial. Amoral como un tigre, como una paloma. Aparentemente sólo creyó en la voluntad de poder, en la fiesta de la guerra, en el fervor del delirio. (POSSE, 1978, p.9) ${ }^{15}$.

Neste curto prólogo, temos já a facilitação da estrutura do texto para a compreensão total da personagem com a qual o romance trabalha, pois não é necessário ler as crônicas, as quais servem como referencial histórico para a escritura da obra, para saber da rebeldia voraz existente nos atos de Aguirre. Contudo, o experimentalismo do autor, e nesse caso representado, principalmente, pela atemporalidade e pela paródia, atuam desde o início para romper com a importância do conteúdo historiográfico. Nesse sentido, e já de forma paródica, a narrativa é recriada sob um novo pano de fundo, em um contexto histórico cinco séculos posteriores, o que permite que as personagens se modifiquem e experimentem novas ações e sensações.

Para dar conta desse experimento, o autor insere na narrativa o "Eterno Retorno do Mesmo", que, como ele mesmo explica, "[...] es una espiral espacio-temporal [...]"16 (POSSE, 1978, p. 9). Este recurso abrange tanto o campo do espaço quanto o do tempo e, de forma circular, possibilita o retorno das personagens à vida e, consequentemente, aos papeis que em tempos remotos desempenharam:

El viejo Lope de Aguirre que regresa al campamento de su combate nocturnal contra los muertos encuentra en la primera claridad los bultos de su tropa dormida en ese aire espeso y empapado de la selva [...]. Sudan envueltos en mantas y cueros para evitar mosquitos [...]. Otros se habian decidido por ilusorias brisas y dormitaban en las ramas altas de las que a veces caían sobre lecho de fango como descomunales chirimoyas maduras. ${ }^{17}$ (POSSE, 1978, p. 14-15).

\footnotetext{
${ }^{15}$ Nossa tradução livre: Lope de Aguirre (1513?-1561). Denominou-se o Tirano, o Traidor, o Peregrino, Antiimperialista, declarou guerra da selva amazônica, rodeado de macacos, a Felipe II, fundando "o primeiro território livre da América". Demonista, Erotômano tímido, mas resistente. Rebelde. Sua crueldade é proverbial. Imoral como um tigre, como uma pomba. Aparentemente só creu na vontade de poder, na festa da guerra, no fervor do delírio. [...]

${ }^{16}$ Nossa tradução livre: [...] é uma espiral espaço-temporal [...].

${ }^{17}$ Nossa tradução livre: $\mathrm{O}$ velho Lope de Aguirre que regressa ao acampamento de seu combate noturno contra os mortos encontra na primeira claridade os vultos de sua tropa adormecida nesse ar espesso e empapado da selva [...]. Surgem envoltos em mantas e peles para evitar mosquitos [...]. Outros haviam decidido por ilusórias
} 
O experimentalismo formal do autor não se limita somente a essa alteração em espiral de espaço e tempo, mas, também, na transmutação da personagem: enquanto que nas crônicas Lope de Aguirre é um ser quase sem sentimentos, raso e desumano, no romance ele é levado a vivenciar novos ambientes e amores, bem como a lidar com conflitos internos e externos. Isso nos permite visualizar algumas facetas, mesmo que ficcionais, que o discurso historiográfico inibe.

$\mathrm{Na}$ narrativa, são essas facetas, ligadas às lembranças do passado, que ocupam o papel de alternantes entre o perfil tirânico, criado pelas crônicas, e o perfil libertário, ensaiado no romance. Um exemplo disso é o relacionamento amoroso entre Lope e Sór Ángela, o qual só passa a ser consumado após um momento de epifania em que Aguirre se dá conta de que a raiva interior que sentia não era apenas por seu plano de libertação da América não ter se concretizado, mas pelas coisas pessoais que deixou de fazer para se dedicar a esse projeto, fatos que encontramos na segunda parte da obra intitulada La vida personal.

Essa parte marca um ponto crítico de ruptura entre um Aguirre "tirano" e outro que pode ser denominado "peregrino". Isso se dá não com referência às nomenclaturas auto atribuídas por Aguirre em sua carta ao rei Felipe II, mas pelo fato de o primeiro estar calcado em sua origem, e o segundo por fugir em busca de desfazer esse eterno retorno. Sobre essa primeira parte, Aracil Varón (2004, p. 31), escreve que

[...] la rebelión de Aguirre no es el tema, sino el punto de partida: Aguirre "regresa" de entre los muertos para organizar una nueva expedición, convirtiéndose así el personaje en hilo conductor de una obra que revisa lo que fue el descubrimiento y la conquista, pero también, en una concepción cíclica del tiempo, recorre cinco siglos de la historia de América. ${ }^{18}$

Em suma, essa revisão da história, a qual abrange cinco séculos posteriores ao ano de 1560, é decisiva no experimento que a obra propõe, justamente, pela desconstrução da linearidade histórica e pela inserção de personagens inexistentes na historiografia, isso no que se refere à personagem, pois, ao mesmo tempo em que revive os fatos, também os modifica. Tal condição altera não somente o mito construído, mas permite questionar a verdade absoluta representada nas crônicas, verdade esta que, para Lope, não poderia se ter dada por concluída.

brisas e dormiam nos galhos altos dos que às vezes caiam sobre um leito de lama como gigantescas pinhas maduras.

${ }^{18}$ Nossa tradução livre: [...] a rebelião de Aguirre não é o tema, se não o ponto de partida: Aguirre "regressa de entre os mortos para organizar uma nova expedição, convertendo-se assim a personagem em fio condutor de uma obra que revisa o que foi o descobrimento e a conquista, mas também, em uma concepção cíclica do tempo, recorre cinco séculos da história da América.

Anu. Lit., Florianópolis, v. 22, n. 2, p. 121-135, 2017. ISSNe 2175-7917 
[...] nada, la nada... Ahora parecía recordar: ;Y la rabia por lo que no se tuvo, por lo que no se hizo, por los amores, por las venganzas, por todo lo que hubo bueno o malo! ;El oro, las mujeres, El Dorado! ;Yo digo que nada está descubierto! iQue nada está concluido! ${ }^{19}$ (POSSE, 1978, p. 16).

Em linhas gerais, com base nas descrições das crônicas se torna visível a dificuldade em resgatar um perfil que não seja o demonizado, o tirânico, o cruel e assassino. No entanto, ao fazer um revisionismo por meio da experimentação com o novo romance histórico, alterando, assim, o ponto de vista e a recepção e considerando-se o contexto sócio histórico de descolonização, podemos notar que o ato de rebeldia maligna na verdade já era um indício da grande luta pela libertação do domínio e da influência que germinou na América Latina. No velho Lope de Aguirre podemos ter um símbolo dessa independência árdua, cuja luta foi sufocada por muito tempo pela imposição do império colonizador e pelos dogmas submissivos da igreja católica.

É pelo revisionismo literário que a imagem discursiva de Aguirre, aquela que emerge das linhas condenatórias dos cronistas, perde a robustez e o status de verdade absoluta acarretado pela importância que os documentos históricos carregam consigo. Através da verossimilhança com a qual os romances são construídos, as possibilidades de compreensão da história se ampliam, isso faz desvanecer a visão unilateral formulada pelo texto historiográfico e abre espaço para lacunas e questionamentos até então não plausíveis.

Em conclusão, reiteramos a proficuidade de que se valem os estudos de críticos literários como Amado Alonso (1984), Aínsa (1991) e Menton (1993), abordados nessa pesquisa, em perceber os aspectos que afloram no romance histórico, especificamente na modalidade do novo romance histórico latino-americano, como a revisitação do passado, a dissolução do tempo e o emprego da paródia, pois, é com ferramentas como essas que personagens históricas, como o velho Lope de Aguirre, (re)significam-se em novos matizes e se reconstroem em cenários mais hospitalários.

\section{Referências}

AÍNSA, Fernando. La nueva novela histórica latinoamericana. México: Plural, 1991.

ALONSO, Amado. Ensayo sobre la novela histórica. Madrid: Editorial Gredos S. A., 1984.

\footnotetext{
${ }^{19}$ Nossa tradução livre: [...] nada, o nada... Agora parecia lembrar: E a raiva pelo que não teve, pelo que não se fez, pelos amores, pelas vinganças, por tudo o que foi bom ou mal! O ouro, as mulheres, El Dorado! Eu digo que nada está descoberto! Que nada está concluído!
} 
ARACIL VARÓN, Maria Beatriz. Abel Posse: de la crónica al mito de américa. Alicante: Compobell, 2004.

CRESPO SOLANA, Ana. La Casa de Contratación y la Intendencia General de la Marina en Cádiz (1717-1730). Cádiz: Universidad de Cádiz, 1996.

ESTEVES, Antonio. R. Lope de Aguirre: da história para a literatura. 1995. Tese (Doutorado em Letras). São Paulo: FFLCH-USP, 1995.

JOS, Emiliano. La Expedición de Ursúa a El Dorado y la Rebelión de Lope de Aguirre. Huesca: Imprenta V. Campo, 1927.

MAPEL GONZÁLEZ, Elena; ESCANDELL TUR, Neus. Lope de Aguirre: crónicas 15591561. Barcelona: Universidad de Barcelona, 1981.

MENTON, Seymour. La Nueva Novela Histórica de la América Latina: 1979-1992. México: Editora do Fondo de Cultura Económica, 1993.

NEIRA, Hernán. O indivíduo inquietante sob o signo de Lope de Aguirre. Tradução de Luci Collin. Curitiba: Editora UFPR, 2013.

OTERO SILVA, Miguel. Lope de Aguirre: El príncipe de la libertad. Caracas: Biblioteca de Ayacucho, 1979.

POSSE, Abel. Daimón. Barcelona: Plaza \& Janés Editores S. A., 1978.

TACCONI, Maria del Carmen. Historiografía y ficción en nuevas novelas históricas argentinas. Tucumán: Universidad Nacional de Tucumán, 2013.

VÁZQUEZ, Francisco; ALMESTO, Pedrarias de. Jornada de Omagua y Dorado: crónica de Lope de Aguirre. Madrid: Miraguano, 1986.

The new Latin American historical novel: the deconstruction of a demonized profile built bythe chronicles between the years of 1559 and 1561

Abstract: By analyzing the literary piece Lope de Aguirre: Crónicas (1559-1561), by Mampel González and Escadell Tur (1981) we aim to verify this European conqueror profile that names the book. With the main focus on Aguirre, the six chronicles related in the book present the trajectory and the happenings in Pedro de Ursúa's expedition, in 1560, in which he had the mission of finding the treasures of El Dorado. When he established a vital link with Peru region, Aguirre, in a letter do the Spanish Crown, denaturalizes himself from his domains, a fact that coincides with a pre-declaration of Independence of the American territory. Due to the course the expedition has taken, Aguirre is betrayed by his fellows, the ones who wrote texts full of convictions against the fragmented character. Based on that, this bibliographical investigation tries to recover Aguirre's discursive image in the chronicles mentioned in order to, comparatively with the data from these chronicles, make reference to the historical novels like Daimón, by Abel Posse (1978) and Lope de Aguirre: Príncipe de la Libertad, by Miguel Otero Silva (1979). 
Keywords: New Latin American Historical Novel. Lope de Aguirre. Chronicles (1559 1561). Daimón (1978). Lope de Aguirre: Príncipe de la Libertad (1979).

Recebido em: 23/04/2017

Aprovado em: 24/10/2017

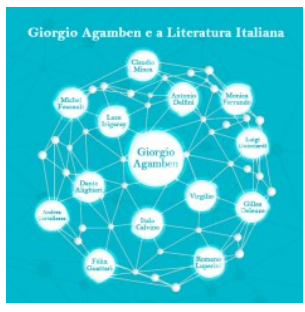

